\section{Initial bromocriptine did not change mortality in early, mild Parkinson's disease}

Lees AJ, Katzenschlager R, Head J, et al, on behalf of the Parkinson's Disease Research Group of the United Kingdom. Ten-year follow-up of three different initial treatments in de-novo PD. A randomized trial. Neurology 2001 Nov 13;57:1687-94.
Source of funding: Parkinson's Disease Society of the United Kingdom.

For correspondence: Professor A J Lees,
University College London and Royal Free Medical School, London, UK. a.lees@ion.ucl.ac.uk.

\section{Design}

Randomised \{allocation concealed*\}†, blinded \{data safety and monitoring committee $\} \nmid, *$ controlled trial with a mean 9.2 years of follow up.

\section{Setting}

UK.

\section{Patients}

782 patients with a clinical diagnosis of PD. Exclusion criteria were failure to respond to an adequate trial of dopaminergic drugs or incapacitating cognitive impairment.

\section{Intervention}

249 patients were allocated to levodopa alone, 271 to levodopa plus selegiline, and 262 to initial bromocriptine. 104 patients in the bromocriptine group were rerandomised to 1 of the other 2 treatment groups after bromocriptine was withdrawn, but all patients were analysed in the groups to which they were initially randomised.

\section{Main outcome measures}

Mortality, disability, and adverse effects.

\section{Main results}

Analysis was by intention to treat. The groups did not differ for mortality (table). At 3 years, those assigned to initial bromocriptine had worse disability scores than those assigned to levodopa alone (difference in adjusted mean Webster score $1.3,95 \%$ CI 0.4 to 2.1 ). This difference was no longer statistically significant at 9 years $(0.2$, CI -1.5 to 1.5 ). At a mean of 9.2 years of follow up, a lower incidence of dyskinesia occurred in patients initially assigned to bromocriptine than in those in the levodopa alone group (relative risk 0.73 , CI 0.57 to 0.93 ). However, when only moderate to severe dyskinesias were analysed, this difference was no longer statistically significant. The groups did not differ for incidence of dystonia or on-off fluctuations.

\section{Conclusions}

In patients with mild, early Parkinson's disease, initial treatment with bromocriptine did not reduce mortality more than levodopa. Disability scores were worse during the first 3 years of treatment with initial bromocriptine.

*See glossary.

†Information provided by author.
Initial bromocriptine (IB) v levodopa alone (L) and levodopa plus selegiline (LS) in early, mild Parkinson's disease at a mean 9.2 years

\begin{tabular}{llll} 
Outcome & Comparisons & $\begin{array}{l}\text { Event rates (person } \\
\text { years at risk) }\end{array}$ & $\begin{array}{l}\text { Unadjusted hazard } \\
\text { ratios }(95 \% \mathrm{Cl})\end{array}$ \\
\cline { 2 - 4 } Mortality & IB $v \mathrm{~L}$ & $58 \%(140) v 51 \%(118)$ & $1.15(0.90$ to 1.47$) \ddagger$ \\
\cline { 2 - 4 } & LS $v$ IB & $61 \%(148) v 58 \%(140)$ & $1.06(0.84$ to 1.34$) \ddagger$ \\
\cline { 2 - 4 } & LS $v \mathrm{~L}$ & $61 \%(148) v 51 \%(118)$ & $1.22(0.95$ to 1.55$) \ddagger$ \\
\hline
\end{tabular}

tNot significant

\section{COMMENTARY}

The study by Lees $e t$ al shows that initiating treatment with bromocriptine or levodopa does not affect mortality rates and that patients who began treatment with levodopa had slightly better motor scores during follow up but a higher incidence of dyskinesias. The study has methodological limitations, the main one being that outcome assessment was not blinded to treatment allocation. Potential bias is suggested by the much higher number of deaths from cerebrovascular disease in the bromocriptine group than in the levodopa group. Dyskinesia scores are rather subjective; the distinction between dystonia and dyskinesias is sometimes difficult.

This study describes a larger number of PD patients and has a longer follow up period than do other studies that compare levodopa and dopamine agonists. These results are in keeping with previous open label studies on bromocriptine ${ }^{1}$ and with more recent controlled studies of new dopamine agonists. ${ }^{2-4}$ The withdrawal rate in the dopamine agonist group in this study is higher than that reported in the controlled trials of cabergoline ( $16 \%$ at $3 \mathrm{y}$ ) and ropinirole ( $27 \%$ at $5 \mathrm{y}$ ). In this report, only $3 \%$ of patients receiving bromocriptine remained on initial treatment after 10 years.

Remarkably, no clinical differences other than potency have emerged among the various dopamine agonists. Therefore, the question arises on the possible generalisation of long term data on bromocriptine. A recently published meta-analysis acknowledged that determining how to start treatment would depend on the relative effect of improving motor disability compared with lessening motor complications. ${ }^{5}$ The present study raises further awareness and concern about the pros and cons of starting PD treatment with a dopamine agonist rather than with levodopa. The results are more pro-levodopa than those published in recent series, which may lead clinicians to consider low doses of levodopa as an alternative initial treatment in PD patients.

Alberto Albanese, MD Istituto Nazionale Neurologico Carlo Besta Milan Italy

1 Rinne UK. Early combination of bromocriptine and levodopa in the treatment of Parkinson's disease: a 5-year follow-up. Neurology 1987;37:826-8.

2 Rinne UK, Bracco F, Chouza C, et al. Early treatment of Parkinson's disease with cabergoline delays the onset of motor complications. Results of a double-blind levodopa controlled trial. The PKDS009 Study Group. Drugs 1998;55:23-30.

3 Rascol O, Brooks DJ, Korczyn AD, et al. A five-year study of the incidence of dyskinesias in patients with early Parkinson's disease who were treated with ropinirole and levodopa. 056 Study Group. N Engl J Med 2000;342:1484-91.

4 Parkinson Study Group. Pramipexole vs levodopa as initial treatment for Parkinson disease: a randomized controlled trial. JAMA 2000;284:1971-3.

5 Mivasaki JM, Martin W, Suchowesky O, et al. Practice parameter: initiation of treatment for Parkinson's disease. An evidence-based review: report of the Quality Standards Subcommittee of the American Academy of Neurology. Neurology 2002;58:11-7. 